\title{
EXPERIMENTAL GLOMERULONEPHRITIS
}

\section{Immunologic Events in the Pathogenesis of Nephrotoxic SERUM NePhrITIS IN THE RaT*, $\ddagger$}

BY DIETRICH K. HAMMER, $\$$ M.D., AND FRANK J. DIXON, M.D.

(From the Division of Experimental Pathology, Scripps Clinic and Research Foundation, La Jolla, California)

Plates 64 to 68

(Received for publication, March 7, 1963)

The possibility of an immunologic basis for human glomerulonephritis is supported by a number of immunologically induced forms of experimental glomerulonephritis. One of the most thoroughly studied of these experimental models is nephrotoxic serum nephritis (NTN) (1).

In this disease, heterologous antikidney, or more precisely, anti-glomerular basement membrane antibody, injected into a recipient reacts with the glomeruli, and may produce immediate structural and functional damage. Superimposed upon this initial immunologic insult by heterologous antibody is an antibody response of the host to the heterologous gamma globulin, resulting in a host antibody interaction with the heterologous gamma globulin fixed in the glomeruli. This second immunologic insult to the glomeruli usually causes further glomerular damage which may be sustained or even increased during the remainder of the life of the animal.

It is not clear whether any other pathogenetic mechanisms are operative in this disease. It has been suggested that the host may also make an autoantibody against his own kidney antigens which might contribute to the renal injury (2-4). The parabjotic transfer of NTN has been cited as support for this possibjlity $(5,6)$. But the recently observed transfer of heterologous gamma globulin (presumably nephrotoxic antibody) from the kidneys of the sick to the kidneys of the well parabiotic partner could explain the transfer of the disease without invoking host antikidney antibodies (7). Further support for an autoantibody against kidney might come from the experiments inducing glomerulonephritis in rats, sheep, and monkeys with injections of autologous, homologous, or heterologous kidney antigens in Freund's adjuvant $(8,9)$. However, a comparison between NTN and this experimental "autoimmune"

* This is publication number 41 from the Division of Experimental Pathology, Scripps Clinic and Research Foundation, La Jolla, California. Presented in part at the 1962 Meetings of the American Association of Immunologists.

$\ddagger$ This work was supported by United States Public Health Service grants and an Atomic Energy Commission contract.

$\S$ Dr. Hammer's present address is the Max Planck Institut für Immunobiologie, Freiburg i/Br., West Germany. 
glomerulonephritis is difficult to make since the pathogenesis of the latter is still not clear.

The present studies were undertaken to examine more closely the various immunologic components in the pathogenesis of NTN. In order to isolate the heterologous antikidney antibody phase of the disease from that produced by the later host response to heterologous protein fixed in the kidney, we employed recipients injected at birth with gamma globulin from the species used to supply the antikidney antibody. By this means tolerance could be established and the host response to heterologous nephrotoxic gamma globulin could be avoided, leaving the initial heterologous phase of renal injury to be studied alone. In the course of these studies it was found that the initial injury produced by the heterologous antikidney antibody reaction in some situations appeared to depend upon the participation of serum complement $\left(C^{\prime}\right)$. Thus, decomplemented recipients could be used to avoid the initial renal damage caused by the reaction of heterologous antikidney antibody with the recipient's kidney and the secondary, host-induced phase of renal injury could be observed alone. Further, it was found in hosts tolerant of the nephrotoxic globulin that the secondary, host antibody-induced phase of NTN could be produced by passive transfer of antibody to the heterologous gamma globulin. In the absence of this antibody, no progressive glomerulonephritis could be produced regardless of the severity of the initial heterologous antikidney injury. Thus, no evidence for the participation of autoantibodies against kidney in the pathogenesis of this disease could be obtained.

\section{Materials and Methods}

1. Rats.-The rats in which NTN was induced were of Sprague-Dawley strain obtained from the Holtzman Rat Company, Madison, Wisconsin. They were 6 to 7 weeks old, weighed 150 to $170 \mathrm{gm}$, and were maintained on Purina lab chow. Pregnant rats from which our newborns were obtained for the induction of tolerance were caged separately and offspring were kept with their mothers until 4 weeks of age.

\section{Proteins.-}

Rabbit gamma globulin (RGG): Pentex Inc., Kankakee, Illinois, Lot R215. This was used for the neonatal induction of tolerance. It contained approximately 95 per cent RGG and 5 per cent beta and alpha globulins by electrophoretic examination.

Human gamma globulin ( $H G G$ ): E. R. Squibb and Sons, New York Lot 1979.

Bovine gamma globulin $(B G G)$ : Armour Pharmaceutical Company, Kankakee, Illinois, Lot C-904.

Rabbit, alpha and beta globulins (RABG) Fr. III: Armour Pharmaceutical Company, Lot 7101.

Crystalline bovine serum albumin (BSA): Armour Pharmaceutical Company, Lot W69102.

Aggregation of $\mathrm{HGG}$ and BGG was achieved by heating at $63^{\circ} \mathrm{C}$ for 15 minutes and precipitating with sodium sulfate (10). The precipitates were dissolved in, and dialyzed against, phosphate-buffered saline $\mathrm{pH} 8$ and then spun in an International PR 2 centrifuge at $20^{\circ} \mathrm{C}$ for 30 minutes at 3000 RPM. The supernate after centrifugation was analyzed and used as the source of aggregated gamma globulin. 
Labeling of RABG with $I^{131}\left(I^{*} R A B G\right)$ was carried out as previously described (11).

3. Antisera.-Rabbit antirat kidney serum (RNTS) was prepared according to the method of Solomon et al. (12); however, no effort was made to use pure glomeruli. The homogenized rat kidneys were washed eight to ten times in saline and the last sediment was resuspended in acetone twice. The kidney antigen was injected into rabbits according to the technique of Baxter and Goodman (13) and the sera of the best responders were pooled. Before use the RNTS was heated for 30 minutes at $56^{\circ} \mathrm{C}$ and absorbed successively with rat erythrocytes and whole rat serum. A dose producing proteinuria of 100 to $200 \mathrm{mg}$ during the first 24 hours after intravenous injection was used as a standard injection, and for the pools of RNTS employed here was $1 \mathrm{ml}$.

The gamma globulin fraction of RNTS (RNT $\gamma$ G) was separated by chromatography on DEAE cellulose columns (14) and $3.5 \mathrm{mg} \mathrm{N}$ induced proteinuria comparable to that caused by $1 \mathrm{ml}$ RNTS.

Duck antirat kidney sera (DNTS) were kindly supplied by Drs. B. C. Seegal (serum 1) and H. C. Goodman (serum 2). Before use, the sera were heated for 30 minutes at $56^{\circ} \mathrm{C}$ and absorbed with rat erythrocytes and whole rat serum. DNTS-1 in a dose of $0.4 \mathrm{ml}$ and DNTS-2 in a dose of $2.5 \mathrm{ml}$ produced an immediate proteinuria somewhat larger than that following $1 \mathrm{ml}$ RNTS (approximately $300 \mathrm{mg} / 24$ hours). For a sustained proteinuria, DNTS-1 was given in doses of $0.4 \mathrm{ml}$ and $0.3 \mathrm{ml}$ on successive days.

Rat anti-RGG was made by injecting three weekly doses of $5 \mathrm{mg}$ RGG in Freund's adjuvant without mycobacteria into 250 to $300 \mathrm{gm}$ Sprague-Dawley rats. Each injection was given in multiple subcutaneous and intradermal sites, including the foot-pads. The rats were bled by puncture of the abdominal aorta 14 days after the last injection. The antibody concentration of the pooled sera was $572 \mu \mathrm{g} \mathrm{Ab} \mathrm{N} / \mathrm{ml}$.

Rabbit anti-BSA was obtained from rabbits hyperimmunized by a series of injections totalling 250 to $300 \mathrm{mg}$ BSA over a 2 to 4 month period and bled 7 days after the last injection. The pooled sera contained $2.1 \mathrm{mg}$ anti-BSA N/ml.

For fluorescent antibody determinations, sheep anti-RGG, rabbit antirat gamma globulin, and rabbit antirat complement $\left(\mathrm{C}^{\prime}\right)$ were labeled with fluorescein as previously described $(15$, 16). The rabbit antirat $C^{\prime}$ was prepared by a modification of the method of McKee and Jeter (17) and absorptions as described by Freedman and Markowitz were used (18).

4. Induction of Tolerance to RGG.-As routine, rats within 3 hours of birth were given an intraperitoneal injection of $40 \mathrm{mg}$ RGG plus subsequent injections during the next 5 days totalling $120 \mathrm{mg}$. To maintain tolerance, additional injections of $50 \mathrm{mg}$ RGG were given 2 and 4 weeks after birth. (In a preliminary experiment a variety of doses of RGG beginning with $20 \mathrm{mg}$ was given to neonatal rats in order to determine the most effective dose for production of tolerance.) Since it was impossible to measure anti-RGG in the serum of most normal rats receiving RNTS, tolerance could not be defined by the failure to detect this response. Rather, it was defined by the inability to form the secondary phase of glomerulonephritis after the injection of RNTS and by the absence of host gamma globulin concentrated in the glomeruli several weeks after injection of RNTS as tested by fluorescent antibody technique.

5. Antibody Determinations.-In some rats injected with RGG at birth antibody to nongamma globulin rabbit serum proteins was present at time of challenge with RNTS. To obtain an estimate of this antibody, a variation of the ammonium sulfate technique of Farr (19) was used employing I*RABG as antigen and performing the precipitation at 40 per cent saturated ammonium sulfate. The I*RABG was absorbed by normal rat serum and was cleared of that portion not soluble in $\mathbf{4 0}$ per cent saturated ammonium sulfate. The results are recorded as per cent of $0.04 \mu \mathrm{g} I^{*} \mathrm{RABG} \mathrm{N}$ bound to host gamma globulin in $0.5 \mathrm{ml}$ of a $1: 10$ dilution of serum. Previous addition of unlabeled RGG purified by DEAE column did not inhibit the specific binding of I*RABG to rat antibody. 
Other antisera were assayed by quantitative precipitin techniques of Heidelberger and associates as described in reference 20 .

6. Titration of Bemolytic Rat $C^{\prime}$.-Blood of individual rats was obtained from the retroorbital venous plexus with glass pipettes and placed at room temperature for 1 hour. The serum was removed after centrifugation and stored at $-70^{\circ} \mathrm{C}$ until used. The titration of $\mathrm{C}^{\prime} \mathrm{H}_{50}$ units was done according to the method described by Osler et al. (21).

7. Urinary Protein Determinations.-Rats were placed in individual metabolism cages containing water but no food and the entire urine output for 24 hours was collected. The amount of protein was determined by sulfosalicylic acid precipitation, comparing the turbidity with a series of standards. The amount of protein was recorded as mg protein/24 hours.

8. Bistology.-Renal tissue taken at autopsy was fixed in Bouin's solution and $5 \mu$ paraffin sections were stained with hematoxylin and eosin or periodic acid-Schiff.

9. Flworescent Antibody Observations.-Sections of kidney taken at autopsy were immediately frozen and then sectioned at $7 \mu$ and stained directly with fluorescein-labeled antibodies as follows: sheep anti-RGG, rabbit antirat gamma globulin, and rabbit antirat $C^{\prime}$. The staining and microscopic procedures to determine specificity were those previously described $(15,16,18)$.

\section{RESULTS}

Our standard procedures to produce NTN, i.e. the intravenous injection of $1 \mathrm{ml}$ RNTS or $3.5 \mathrm{mg} \mathrm{RNT} \gamma \mathrm{G} \mathrm{N}$, caused a proteinuria detectable within 2 hours and resulted in an initial 24 hour urinary protein of 100 to $200 \mathrm{mg}$ in 92 per cent of normal rats. The proteinuria in these rats remained at these levels or gradually increased during a subsequent 12 week observation period (Table I, groups 1 and 4). As demonstrable by fluorescent antibody techniques, RGG was found concentrated and fixed in the glomerular capillary walls within 20 minutes after injection of RNTS and persisted there throughout the period of observation. Host gamma globulin began to concentrate similarly within 5 to 6 days after injection of RNTS and increased within the next several weeks roughly in proportion to the degree of renal injury.

Nature of the Secondary, Host Antibody-Induced Phase of NTN.-In order to study the secondary phase of NTN, rats were injected at birth with RGG to induce specific immunologic tolerance and 6 to 7 weeks later were injected with RNTS or RNT $\gamma$ G. Various doses of RGG at birth were tried. $20 \mathrm{mg}$ RGG given intraperitoneally at birth failed to induce tolerance in any of ten rats as judged by their development of the secondary phase of NTN on challenge with RNTS 6 weeks later. 80 or $120 \mathrm{mg}$ RGG at birth each resulted in an incidence of 67 per cent tolerance 6 weeks later. 40 mg RGG within 3 hours of birth followed by two similar injections within the first 5 days of life plus $50 \mathrm{mg} 2$ and 4 weeks after birth resulted in an incidence of 80 per cent tolerance at age 6 weeks; i.e., 80 per cent failed to develop a secondary phase of NTN. The remaining 20 per cent developed a proteinuria comparable to that seen in normal rats. This latter scheme was used as routine to induce tolerance throughout the rest of the experiments.

111 of 139 rats injected with RGG at birth were tolerant and failed to de- 
velop the second phase of NTN after injection of $1 \mathrm{ml}$ of RNTS (Table I, groups 5 and 6) while the remaining 28 behaved as normals (group 7). 19 of 26 were tolerant and failed to develop a second phase NTN after injection of 3.5 mg RNT $\gamma \mathrm{G} \mathrm{N}$ (Table I, group 2). Both groups of tolerant animals also failed at any time to show host gamma globulin concentrated in glomeruli when observed with fluorescent antibody techniques. If, as seemed likely, this failure to show secondary proteinuria was related to the inability to form anti-RGG it was reasoned that the passive administration of rat anti-RGG to such tolerant rats some time after the injection of RNTS should precipitate a proteinuria.

TABLE 1

Effect of RNT $\gamma G$ or RNTS on Normal Rats and Rats Injected with RGG at Birth

\begin{tabular}{|c|c|c|c|c|c|c|c|c|c|}
\hline \multirow{3}{*}{ Group } & \multirow{3}{*}{ No. of rats } & \multirow{3}{*}{$\underset{\text { birth }}{\text { RGG at }}$} & \multirow{3}{*}{$\begin{array}{l}\text { Anti-kidney } \\
\text { antibody injected }\end{array}$} & \multicolumn{6}{|c|}{ Proteinuria $\mathrm{mg} / 24$ hours } \\
\hline & & & & \multicolumn{6}{|c|}{ Days } \\
\hline & & & & 1 & 3 & 5 & 28 & 56 & 84 \\
\hline 1 & 7 & - & $\mathrm{RNT} \gamma \mathrm{G}^{*}$ & 240 & 131 & 166 & 234 & & \\
\hline 2 & 19 of 26 & + & $\mathrm{RNT} \gamma \mathrm{G}^{*}$ & 131 & 72 & 70 & 13 & $12 \ddagger$ & \\
\hline 3 & 7 of 26 & + & RNT $\gamma \mathrm{G}^{*}$ & 234 & 121 & 134 & 130 & - & \\
\hline 4 & 96 & - & RNTS\& & 153 & 103 & 150 & 187 & 192 & 210 \\
\hline 5 & ( 84 of 139 & + & RNTS\$ & 13 & 9 & 11 & 7 & 6 & 9 \\
\hline 6 & $\{27$ of 139 & + & RNTS\$ & 104 & 64 & 42 & 15 & 12 & 14 \\
\hline 7 & 28 of 139 & + & RNTS\& & 149 & 111 & 137 & 169 & 182 & 199 \\
\hline
\end{tabular}

* A single intravenous dose of $3.5 \mathrm{mg} \mathrm{N}$ rabbit nephrotoxic gamma globulin.

$\ddagger$ In one of nineteen rats proteinuria reappeared 8 weeks after injection with nephrotoxic gamma globulin.

$\$$ A single intravenous dose of $1 \mathrm{ml}$ rabbit nephrotoxic serum.

The results of such experiments are shown in Table II. 6-week-old rats injected with RGG at birth which failed to develop immediate proteinuria after injection of RNTS were given $2.3 \mathrm{mg}$ rat anti-RGG $\mathrm{N}$ either 3 or 5 days after injection of $1 \mathrm{ml} \mathrm{RNTS}$. In all these rats a severe proteinuria appeared promptly after the passive administration of the rat anti-RGG. RNTS given alone to tolerant rats produced no secondary proteinuria nor did normal rabbit serum followed 3 days later by rat anti-RGG. Rat anti-RGG given 3 days after RNTS to normal rats had no observable effect on the level of secondary proteinuria.

Since in rats tolerant to RGG the response of the host to heterologous nephrotoxic globulin was eliminated it was possible to see whether severe immunologic injury to the kidney would initiate an autoimmune response against kidney capable of perpetuating renal disease. In Table III, such observations are presented. Two and four times the usual dose (3.5 mg N) of RNT $\gamma \mathrm{G}$ were given to control rats and rats receiving $\mathrm{RGG}$ at birth. In the control rats the 
increased dose of $\mathrm{RNT} \gamma \mathrm{G}$ caused severe immediate and late proteinuria. In all ten of the rats given RGG at birth the immediate proteinuria was similar to that seen in controls but within 5 days in six of these the loss of protein diminished and by 6 weeks was only one-sixth to one-eighth of that seen in the controls and was approaching normal values. Thus, even very severe immunologic injury to the glomeruli by $\mathrm{RNT} \gamma \mathrm{G}$ did not appear to initiate a self perpetuating kidney disease in the RGG-tolerant rat.

Some observations made with DNTS also supported the idea that the second phase of NTN could be attributed to the host antibody response to the heterologous globulin. First of all it was found that two injections on successive days

TABLE II

Effect of Rat Anti-RGG on Development of Nephrotoxic Nephritis in Normal Rats and Rats Given RGG at Birth

\begin{tabular}{|c|c|c|c|c|c|c|c|c|c|c|}
\hline \multirow{3}{*}{$\begin{array}{l}\text { No. of } \\
\text { rats }\end{array}$} & \multirow{3}{*}{$\begin{array}{l}\text { Injected with } \\
\text { RGG at birth }\end{array}$} & \multirow{3}{*}{ Treatment } & \multirow{3}{*}{$\begin{array}{l}\text { Rat anti- } \\
\text { RGG at }\end{array}$} & \multicolumn{7}{|c|}{ Proteinuria $\mathrm{mg} / 24$ hours } \\
\hline & & & & \multicolumn{7}{|c|}{ Days } \\
\hline & & & & 1 & 3 & 5 & 7 & 14 & 28 & 56 \\
\hline $9 \ddagger$ & + & RNTS & 3 days & 17 & 11 & 146 & 122 & 139 & 157 & 140 \\
\hline $5 \ddagger$ & + & RNTS & 5 days & 13 & 12 & 15 & 137 & 128 & 131 & - \\
\hline 4 & + & NRS & & 1 & 6 & 2 & 一 & 3 & 一 & 13 \\
\hline $5 \ddagger$ & + & RNTS & none & 6 & 3 & 6 & 7 & 11 & 12 & 14 \\
\hline 9 & - & RNTS & 3 days & 103 & 109 & 129 & 122 & 149 & 159 & 209 \\
\hline 5 & - & RNTS & none & 116 & 92 & 117 & 107 & 158 & 177 & 219 \\
\hline
\end{tabular}

* $4 \mathrm{ml}$ rat anti-RGG (572 $\mu \mathrm{g} \mathrm{Ab} \mathrm{N} / \mathrm{ml})$ given intravenously 3 or 5 days after injection with RNTS or NRS.

$\ddagger$ Only rats showing no immediate proteinuria were selected for these groups.

( 0.4 and $0.3 \mathrm{ml}$ ) of DNTS-1 or one injection of $2.5 \mathrm{ml}$ of DNTS-2 would induce immediate and also secondary NTN to a comparable extent in both normal rats and rats given RGG at birth. This further demonstrated that the administration of RGG at birth did not produce any change in the rats incompatible with a sustained immunologically induced renal disease, providing the necessary immunological ingredients were present. The RGG tolerant rats were perfectly capable of making antibody to duck globulin after one large or two successive small injections of DNTS, as indicated by the accumulation of host globulin in the glomeruli, and thereby causing the second phase of the disease. Second, in the course of the studies with DNTS-1, it was observed that a single injection of $0.3 \mathrm{ml}$ of this serum into normal rats produced an immediate (within 2 hours), severe proteinuria (approximately $300 \mathrm{mg} / 24$ hours) but that renal function returned to normal within 5 days. It seemed likely that 
this failure to develop a sustained renal disease was related to a failure of the rats to respond to the duck gamma globulin after only one small dose of DNTS. This might be explained on the basis of the small dose of antigen ( $0.3 \mathrm{ml}$ serum) and the very brief persistence of duck gamma globulin (19 hour half-life) in rats. If this were so, immunization of rats to normal duck gamma globulin some time after injection of $0.3 \mathrm{ml}$ DNTS should precipitate a sustained second stage NTN. Ten rats received the $0.3 \mathrm{ml}$ DNTS and had a prompt severe proteinuria which cleared within 5 days. At this time each rat was injected subcutaneously and intradermally with $0.5 \mathrm{ml}$ normal duck serum in incomplete

TABLE III

Effect of Large Doses of Nephrotoxic Gamma Globulin on Normal Rats and Rats Given RGG at Birth

\begin{tabular}{|c|c|c|c|c|c|c|c|c|}
\hline \multirow{3}{*}{ RGG at birth } & \multirow{3}{*}{$\begin{array}{l}\mathrm{RNT} \gamma \mathrm{G} \\
\text { injected }\end{array}$} & \multirow{3}{*}{$\begin{array}{c}\text { No. of tolerant } \\
\text { rats }\end{array}$} & \multicolumn{6}{|c|}{ Protein mg/24 hours } \\
\hline & & & \multicolumn{6}{|c|}{ Days } \\
\hline & & & 1 & 3 & 5 & 7 & 21 & 42 \\
\hline & $m g$ & & & & & & & \\
\hline - & 7 & $0 / 7$ & 151 & 172 & 159 & 183 & 250 & 261 \\
\hline- & 14 & $0 / 4$ & 225 & 127 & 234 & 213 & 272 & 408 \\
\hline+ & 7 & $3 / 5^{*}$ & 174 & 109 & 66 & 63 & 53 & 45 \\
\hline+ & 14 & $3 / 5^{*}$ & 309 & 160 & 96 & 104 & 78 & 51 \\
\hline
\end{tabular}

* Urinary protein values from tolerant rats only.

Freund's adjuvant. Within 9 days, six of these ten rats developed a significant proteinuria which was maintained throughout the 8 weeks observation period.

Reactions Involved in the Initial Phase of NTN.-Early in the course of these studies an apparent inconsistency appeared. In rats exposed to RGG at birth, the injection of $\mathrm{RNT} \gamma \mathrm{G}$ invariably produced an immediate proteinuria (Table I, groups 2 and 3) while with injection of RNTS the incidence of immediate proteinuria was only 40 per cent (Table I, groups 5 to 7 ). No abnormalities in blood counts or $\mathrm{C}^{\prime}$ levels were found in RGG-tolerant rats prior to their injection with RNTS which might account for this difference. It seemed likely, therefore, that the host might be reacting to some non-gamma globulin fraction of the RNTS and that this reaction interfered with the development of immediate renal disease.

Analysis of the sera of twelve 6-week-old rats injected with RGG at birth revealed that eight had detectable antibody to RABG and four did not (Table IV, T41, T42, T45, T46). Since the RGG injected at birth and at 2 and 4 weeks of age contained small amounts of alpha and beta globulins, it appears that these contaminants did not induce tolerance but did stimulate an antibody response in some rats. After the injection of RNTS into these rats, six of the 
eight with antibody to RABG showed no increase in proteinuria and two (T29 and T40) showed a questionable rise. Each of the four rats without detectable antibody to RABG showed an immediate significant proteinuria. Thus, it appeared that an incidental antigen-antibody reaction was capable of interfering with the development of the first phase of NTN.

A further attempt to evaluate the role of any circulating antibody against non-gamma globulin rabbit proteins in the failure of these tolerant animals to develop the first stage of NTN was made by removing any such antibodies

TABLE IV

Effect of Antibodies to RABG in Rats Given RGG at Birth on the Development of Nephrotoxic Nephritis

\begin{tabular}{|c|c|c|c|}
\hline \multirow{3}{*}{ Rat No. } & \multirow{2}{*}{\multicolumn{2}{|c|}{$\frac{\text { Proteinuria mg/24 Hours }}{\text { Days }}$}} & \multirow{3}{*}{$\begin{array}{c}\text { Per cent RABG } \\
\text { precipitated }\end{array}$} \\
\hline & & & \\
\hline & 1 & 3 & \\
\hline Т 28 & 14 & 5 & 8 \\
\hline Т 29 & 34 & 12 & 14 \\
\hline T 30 & 9 & 8 & 14 \\
\hline T 31 & 12 & 9 & 15 \\
\hline T 32 & 13 & 5 & 10 \\
\hline $\mathrm{T} 40$ & 34 & 14 & 13 \\
\hline T 41 & 135 & 68 & 3 \\
\hline $\mathrm{T} 42$ & 100 & 48 & 3 \\
\hline T 43 & 17 & 12 & 13 \\
\hline T 44 & 14 & 18 & 18 \\
\hline $\mathrm{T} 45$ & 60 & 54 & 3 \\
\hline$T 46$ & 84 & 36 & 4 \\
\hline
\end{tabular}

* Precipitated with 40 per cent saturated ammonium sulfate at 1:10 dilution of antiserum.

with an injection of $1 \mathrm{ml}$ normal rabbit serum (NRS) 1 day before the injection of RNTS. It would not be expected that more antibody would be formed within 1 day; however, if there was any $\mathrm{C}^{\prime}$ depletion as a result of the NRS injection, this should have been replaced by the time RNTS was injected. All of twelve tolerant rabbits receiving NRS and 1 day later RNTS developed an immediate proteinuria with levels $>100 \mathrm{mg}$ during the first 24 hours.

The precise effect of the reaction of circulating antibody to the non-gamma globulins of RNTS on the levels of serum $\mathrm{C}^{\prime}$ was not determined. However, it seemed likely that $C^{\prime}$ depletion by this reaction could explain the failure of 60 per cent of rats given RGG at birth to develop the initial stage of NTN following injection of RNTS. In both normal rats and rats receiving RGG at birth there were comparable falls in serum $\mathrm{C}^{\prime}$ after injection of RNTS. Both groups 
of rats had preinjection $\mathrm{C}^{\prime} \mathrm{H}_{50}$ levels of 40 to 50 units and these dropped to little more than 10 per cent of control levels in 15 minutes, to $<10$ per cent in 3 hours, 10 to 15 per cent in 6 hours, and back to near normal values in 24 hours. The possibility existed that in the group receiving RGG at birth the formation of RABG-antibody complexes after injection of RNTS utilized enough $\mathrm{C}^{\prime}$ to prevent effective participation of $\mathrm{C}^{\prime}$ and/or other serum factors in the RNTS versus glomerular basement membrane reaction. In normal rats, apparently the antitissue antibody reaction alone exhausted the serum $\mathrm{C}^{\prime}$ while in the RGG-tolerant rats the incidental anti-RABG reactions competed with the anti-tissue reactions for available $C^{\prime}$. As has been shown earlier, RNTS

TABLE V

Effect of Aggregated HGG or BGG or BSA-Anti-BSA Reaction on Hemolytic Serum Complement in Normal Rats

\begin{tabular}{|c|c|c|c|c|c|c|c|c|}
\hline \multirow{3}{*}{ Treatment } & \multirow{3}{*}{$\begin{array}{l}\text { No. of } \\
\text { rats }\end{array}$} & \multicolumn{7}{|c|}{ Serum complement- $\mathrm{C}^{\prime} \mathrm{H}_{50}$ units/ml } \\
\hline & & \multirow{2}{*}{$\begin{array}{c}\text { Pretreat- } \\
\text { ment }\end{array}$} & \multicolumn{6}{|c|}{ Posttreatment } \\
\hline & & & $15 \mathrm{~min}$. & $30 \mathrm{~min}$. & $1 \mathrm{hr}$. & 2 hrs. & $6 \mathrm{hrs}$. & $24 \mathrm{hrs}$. \\
\hline Aggregated HGG* & 28 & 47 & 4 & & & 3 & 9 & 43 \\
\hline Aggregated BGG* & 8 & 48 & 42 & & 47 & & 44 & 51 \\
\hline BSA-anti-BSA $\ddagger$ & 16 & 50 & 13 & 5 & & 5 & 10 & 46 \\
\hline
\end{tabular}

* Given intravenously $2.5 \mathrm{mg} \mathrm{N}$.

$\$ 1.0 \mathrm{mg}$ rabbit anti-BSA $\mathrm{N}$ given intravenously 2 hours prior to 20 times an equivalent amount of BSA.

absorbed with rat erythrocytes and serum reacts not only with kidney but also with non-renal tissues since injection of RNTS into bilaterally nephrectomized rats causes a fall in serum $\mathrm{C}^{\prime}$ comparable to that occurring in intact rats (22).

Since it appeared that the depletion of serum $\mathrm{C}^{\prime}$ by the incidental antigenantibody reaction might be preventing the full development of the initial phase of renal injury, other means of decomplementing rats prior to injection of RNTS were tried. The effects of $2.5 \mathrm{mg} \mathrm{N}$ of heat-aggregated HGG or BGG or of the interaction of $1 \mathrm{mg}$ anti-BSA N-BSA on the serum $\mathrm{C}^{\prime}$ of normal rats are shown in Table V. Intravenously injected aggregated HGG removed 93 per cent of the $C^{\prime}$ within 15 minutes, the level remained low for at least 6 hours and returned to normal within 24 hours. Aggregated BGG as would be expected had no effect on serum $\mathrm{C}^{\prime}$ (23). The BSA-anti-BSA interaction removed 90 per cent of the $\mathrm{C}^{\prime}$ within 30 minutes with return to normal levels within 24 hours. Blood counts on normal rats 3 and 24 hours after injection of $2.5 \mathrm{mg}$ aggregated HGG $N$ revealed no significant changes in leukocyte or platelet counts. Table VI illustrates the effect of injections of aggregated HGG or 
BGG 1 hour prior to the injection of RNTS on the development of NTN. Those rats getting aggregated HGG and then the regular dose of RNTS showed no significant proteinuria 1 and 3 days later, but by 5 days the amount of urinary protein had increased and 2 and 4 weeks after injection the second phase of NTN was well developed (group 1). However, aggregated HGG-pretreated rats receiving three times the usual dose of RNTS did develop some early proteinuria (162 $\mathrm{mg} / 24$ hours) (group 2), but not nearly as much as a comparable dose of RNTS produced in non-HGG-pretreated rats $(392 \mathrm{mg} / 24$ hours) (group 6). The injection of aggregated HGG alone had no effect on urinary protein (group 3). The injection of aggregated BGG 1 hour prior to

TABLE VI

Effect of Aggregated $B G G$ and BGG on Early Proteinuria in Normal Rats Injected with RNTS

\begin{tabular}{|c|c|c|c|c|c|c|c|c|}
\hline \multirow{3}{*}{$\begin{array}{l}\text { Aggregated } \gamma \text { - } \\
\text { globulin injected }\end{array}$} & \multirow{3}{*}{$\begin{array}{l}\text { No. of } \\
\text { Rats }\end{array}$} & \multirow{3}{*}{ Treatment } & \multicolumn{6}{|c|}{ Proteinuria mg/24 hours } \\
\hline & & & \multicolumn{6}{|c|}{ Days } \\
\hline & & & 1 & 3 & 5 & 7 & 14 & 28 \\
\hline HGG & 39 & RNTS & 9 & 10 & 60 & 80 & 160 & 188 \\
\hline HGG & 6 & RNTS $(3 \mathrm{ml}$ ) & 162 & 84 & 136 & 154 & 196 & 228 \\
\hline HGG & 12 & None & 2 & - & 2 & 1 & 2 & 2 \\
\hline BGG & 8 & RNTS & 140 & 114 & 137 & 168 & 186 & - \\
\hline None & 26 & RNTS & 131 & 101 & 119 & 115 & 169 & 177 \\
\hline None & 6 & RNTS $(3 \mathrm{ml})$ & 392 & 296 & 238 & 307 & 402 & 456 \\
\hline
\end{tabular}

* $2.5 \mathrm{mg} \mathrm{N}$ of aggregated gamma globulin given 1 hour prior to RNTS.

RNTS had no effect on the course of the subsequent NTN, for both initial and secondary phases of the disease developed fully (group 4).

Fluorescent antibody observations confirmed these immunologic data. In control rats and those pretreated with BGG before injection of RNTS, signifcant concentrations of host $\mathrm{C}^{\prime}$ were regularly found in the glomeruli as early as 20 minutes after injection of RNTS (Fig. 6). However, in aggregated HGG pretreated rats with depletion of serum $\mathrm{C}^{\prime}$ before injection of RNTS, fluorescent staining revealed only rare glomeruli with small amounts of detectable host $\mathrm{C}^{\prime}$ (Fig. 7).

The interaction of $1 \mathrm{mg}$ rabbit anti-BSA with 20 times the equivalent amount of BSA given 2 hours later also prevented in large part the development of the first phase of NTN in sixteen normal rats in response to $1 \mathrm{ml}$ RNTS given with the BSA. Abnormal proteinuria first developed 5 days after injection of RNTS and persisted in levels above $100 \mathrm{mg} / 24$ hours during the 4 week observation period. As carried out in these experiments, heat-aggregated $H G G$ gave a more 
reproducible suppression of the primary phase of NTN than did the antiBSA-BSA reaction.

An interesting difference was observed between the initial phases of NTN produced by RNTS and by DNTS. While the injection of RNTS into normal rats caused a prompt fall in serum $\mathrm{C}^{\prime}$, a dose of DNTS sufficient to cause a twofold greater immediate (within 2 hours) proteinuria caused no detectable fall in serum $C^{\prime}$ in agreement with earlier reports (24). Eight rats receiving 0.3 to $0.6 \mathrm{ml}$ DNTS-1 had initial 24 hour proteinuria averaging $>300 \mathrm{mg}$, yet serum $\mathrm{C}^{\prime}$ levels showed no drop during the first 24 hours after injection. Also, rats pretreated with $0.4 \mathrm{mg}$ aggregated $\mathrm{HGG} \mathrm{N} 1$ hour before receiving $0.4 \mathrm{ml}$ DNTS-1 all developed a severe, immediate proteinuria in spite of the fact that $\mathrm{C}^{\prime}$ had been virtually eliminated from the circulation. As mentioned above, a group of similarly aggregated HGG pretreated rats given $1 \mathrm{ml}$ RNTS uniformly failed to develop an immediate proteinuria.

Morphologic Observations.--In general our morphologic observations were similar to those previously reported by Smadel (25), Heymann and Lund (26), and Hasson, Bevans, and Seegal (27) and were consistent with the above immunologic and functional data. Representative rats were sacrificed at appropriate intervals during most of the experiments and their kidneys observed by light microscopy.

Kidneys taken from rats in the initial phase of NTN, regardless of the exact experimental manipulations causing the disease, all showed comparable changes. Noticeable during the first 2 to 3 days after the injection of RNTS, RNT $\gamma \mathrm{G}$, or DNTS was a proliferation and hypertrophy of glomerular capillary endothelium and a sprinkling of leukocytes within some of the glomeruli (Figs. 1 and 2). By the end of 1 week most of the glomerular capillaries were occluded by endothelial cells and a thickened capillary basement membrane (Fig. 3). Rarely, fibrin thrombi were found in glomerular capillaries usually associated with severe damage and heavy proteinuria. The proximal convoluted tubules contained protein casts and their epithelium contained hyaline droplets. In RGG-tolerant rats not developing the secondary phase of the disease, these changes were largely reversible and with the disappearance of proteinuria at 2 to 4 weeks the renal architecture approached normal. Only occasional, slightly scarred or distorted glomeruli persisted in RGG-tolerant rats (Fig. 4). In $\mathrm{C}^{\prime}$ depleted rats not developing early proteinuria, there was only a slight increase in glomerular cellularity in the first 3 to 5 days after injections of RNTS. By fluorescent antibody staining, heterologous nephrotoxic gamma globulin was demonstrable on the host's glomerular capillary walls within 20 minutes of injection regardless of whether the initial phase of NTN was developing or not and this material remained so localized throughout the period of observation (Fig. 5) $(28,29)$. In recipients with normal levels of serum $C^{\prime}$ developing the initial phase, $\mathrm{C}^{\prime}$ was also demonstrable in the glomeruli (Fig. 6), while in de- 
complemented animals not showing early renal injury little or no $\mathrm{C}^{\prime}$ could be found (Fig. 7).

The secondary phase of NTN appeared to begin 5 to 6 days after the injection of nephrotoxic antibody in those rats capable of responding to the heterologous gamma globulin. At this time host gamma globulin could first be demonstrated in the glomerular capillary walls in agreement with earlier reports (28). With the advent of this second immunologic insult, there was an increasing thickness of glomerular basement membranes and Bowman's capsule. Lobulation of the glomerular capillary tufts occurred and there was an increase in proliferation of glomerular epithelial and endothelial cells. Capsular crescent formation with adhesions to glomerular tufts were common (Fig. 8) and this scarring process led to complete obliteration of many glomeruli. The tubules contained many large dense protein casts and became markedly distorted and/ or atrophied. Late in the disease an interstitial mononuclear infiltrate appeared in some rats. When the second phase was set off by passive transfer of rat antiRGG the same morphologic changes occurred as when the host itself responded to the heterologous gamma globulin (Fig. 9). The early deposits of host gamma globulin appeared as finely granular sprinklings of fluorescence in the glomerular capillary walls which increased in amount with time (Fig. 10). In some advanced lesions, there appeared to be a homogeneous increase of host gamma globulin throughout the entire glomerulus. In the absence of a secondary phase, concentrations of host gamma globulin were not demonstrable in glomeruli.

\section{DISCUSSION}

These observations support the prevalent concepts of the pathogenesis of NTN: (a) that the immediate phase is caused by interaction of heterologous antikidney antibody with glomerular antigens, and $(b)$ that the later, continuing phase is caused by antibodies formed by the host against the heterologous gamma globulin, which presumably react with the foreign protein fixed in the glomerulus. In addition, several features of these immunologic events have been further defined. First, it appears that there may be a difference in the mechanisms by which RNTS and DNTS produce immediate nephrotoxic injury. The DNTS used here produced immediate morphologic and functional renal injury (27) comparable to that produced by RNTS. RNTS appears to not only utilize $\mathrm{C}^{\prime}$, as noted by previous workers (22), buit also to be dependent upon the presence of serum $\mathrm{C}^{\prime}$ to produce glomerular injury (30). Any of several methods of decomplementing rats prior to, or simultaneously with, the injection of RNTS prevented the development of immediate glomerular injury. And even when $\mathrm{C}^{\prime}$ levels returned to normal 24 hours after injection of RNTS no proteinuria developed, as if the glomerular bound nephrotoxic antibody was no longer able to react with $\mathrm{C}^{\prime}$ and produce a phlogogenic stimu- 
lus. DNTS, on the other hand, readily induces immediate renal injury in the decomplemented rat. In addition, even in large doses it appears to utilize no serum $\mathrm{C}^{\prime}$ as observed with hemolytic $\mathrm{C}^{\prime}$ determinations in the primary phase of the disease (24). While such $\mathrm{C}^{\prime}$ determinations cannot reveal small changes in individual components of $\mathrm{C}^{\prime}$ which might result from administration of DNTS, they would seem to indicate a gross difference in $\mathrm{C}^{\prime}$ utilization by the two antisera. The fact that very large doses of RNTS could produce some glomerular injury in decomplemented rats suggests that rabbit antibodies, if in great enough concentration, either could produce injury without the participation of $\mathrm{C}^{\prime}$ or that the small amounts of $\mathrm{C}^{\prime}$ remaining in the decomplemented rats were sufficient in the presence of much rabbit antibody to cause injury. In either case the pathogenetic mechanisms operating in decomplemented rats receiving RNTS were much less effective in causing glomerular injury than were those operating in rats receiving RNTS in the presence of normal $C^{\prime}$ levels.

Second, as far as could be determined, the secondary, sustained phase of NTN is dependent upon an antibody response to the heterologous globulin and not to any host antikidney antibody response. The anti-heterologous globulin response was detectable as early as 5 to 6 days after injection of RNTS into normal rats by the identification of host gamma globulin concentrating in the glomeruli and by progressive renal injury. Those rats made tolerant to RGG (80 per cent of those injected with RGG at birth) developed neither a secondary phase of NTN nor an accumulation of host gamma globulin in the glomeruli. However, the morphologically and functionally complete secondary phase of the disease could be transferred to such tolerant rats by passive administration of rat anti-RGG several days after injection of RNTS. It is of interest that a single injection of rat anti-RGG induced a secondary renal injury which persisted throughout an 8 week observation period. In normal rats given a single small dose of DNTS, primary but not secondary renal injury developed, apparently because the single injection did not stimulate a sufficient anti-duck gamma globulin response. However, immunization of such rats several days after receiving DNTS with normal duck serum in adjuvant resulted in development of a delayed secondary phase of NTN. Apparently the delayed immunization with duck serum caused an anti-duck gamma globulin response. Similarly, the secondary phase of the disease could be produced by two successive daily injections of DNTS which presumably could initiate an anti-duck gamma globulin response in the recipient rats. The secondary phase of disease after either RNTS or DNTS appeared to be related to an antibody response to normal RGG or duck serum proteins and not to an antibody response against antigens specifically present in the NTS or in the host's kidneys $(5,31)$. It appears that even severe renal injury produced by NTS is not sufficient in itself to initiate an antikidney response by the host capable of 
causing sustained renal disease. In the case of rats tolerant to RGG, even doses of $\mathrm{RNT}_{\gamma} \mathrm{G}$ four times those capable of the usual degree of renal injury could not produce a continuing severe nephritis. Nor could a single small dose of potent DNTS stimulate a continuing nephritis. While other kinds of renal injury might possibly initiate an injurious autoimmune antikidney response it seems likely that in the usual operation of NTN no such response is initiated by the primary renal injury.

SUMMARY

The primary phase of nephrotoxic serum nephritis produced by rabbit nephrotoxic serum appears to be dependent to a great extent, but not completely, upon the participation of serum complement. On the other hand, duck nephrotoxic serum produces its primary renal injury without detectable utilization of or dependence upon serum complement.

The secondary phase of nephrotoxic serum nephritis appears to be largely or entirely dependent upon the host's antibody response to the heterologous gamma globulin fixed in the glomeruli. No evidence could be obtained for the existence of an autoimmune antikidney response by the host in this experimental model.

\section{BIBLIOGRAPHY}

1. Masugi, M., Uber die experimentelle Glomerulonephritis durch das spezifische Antinieren-Serum, Beitr. path. Anat. u. allg. Path., 1933-34, 92, 429.

2. Fischel, E. E., Immune reactions in human glomerulonephritis, J. Chron. Dis., 1957, 5, 34.

3. Lange, K., Gold, M., Weiner, D., and Simon, V., Auto-antibodies in human glomerulonephritis, J. Clin. Inv., 1949, 28, 50.

4. Liu, C. T., and McCrory, W. W., Autoantibodies in human glomerulonephritis and nephrotic syndrome, J. Immunol., 1958, 81, 492.

5. Lange, K., Wachstein, M., and McPherson, E., Immunologic mechanism of transmission of experimental glomerulonephritis in parabiotic rats, Proc. Soc. Exp. Biol. and Med., 1961, 106, 13.

6. Pfeiffer, E. F., Schöflling, K., Sandritter, W., Schroeder, J., Steigerwald, H., and Wolf, L., Studien zur Übertragung der Masugi-nephritis der Ratte: die Übertragung durch kurzdauernde Parabiose, Z. ges. exp. Med., 1954, 124, 471.

7. Seegal, B. C., Heterologous kidney-localizing antibody in experimental nephritis: old facts and present concepts, in 3rd International Symposium on Immunopathology (Peter Miescher and Pierre Grabar, editors), Benno Schwabe \& Co., Basle, 1963, to be published.

8. Heymann, W., Hackel, D. B., Harwood, S., Wilson, S. G., and Hunter, J. L. P., Production of nephrotic syndrome in rats by Freund's adjuvants and rat kidney suspension, Proc. Soc. Exp. Biol. and Med., 1959, 100, 660.

9. Steblay, R. W., Glomerulonephritis induced in sheep by injections of heterologous glomerular basement membrane and Freund's complete adjuvant, $J$. Exp. 
Med., 1962, 116, 253. Localization in human kidney of antibodies formed in sheep against human placenta, $J$. Immunol., 1962, 88, 434.

10. Christian, C. L., Characterization of the "reactant" (gamma globulin factor) in the F II precipitin reaction and the F II tanned sheep cell agglutination test, J. Exp. Med., 1958, 108, 139.

11. Talmage, D. W., and Maurer, P. H., $I^{131}$-labelled antigen precipitation as a measure of quantity and quality of antibody, J. Infect. Dis., 1953, 92, 288.

12. Solomon, D. H., Gardella, J. W., Fanger, H., Dethier, F. M., and Ferrebee, J. W., Nephrotoxic nephritis in rats. Evidence for the glomerular origin of the kidney antigen, J. Exp. Med., 1949, 90, 267.

13. Baxter, J. H., and Goodman, H. C., Nephrotoxic serum nephritis in rats. $I$. Distribution and specificity of the antigen responsible for the production of nephrotoxic antibodies, J. Exp. Med., 1956, 104, 467.

14. Sober, H. A., Gutter, F. S., Wyckoff, M. M., and Peterson, E. A., Chromatography of proteins. II. Fractionation of serum protein on anion-exchange cellulose, J. Am. Chem. Soc., 1956, 78, 756.

15. Vazquez, J. J., and Dixon, F. J., Immunohistochemical analysis of amyloid by the fluorescent technique, J. Exp. Med., 1956, 104, 727.

16. Vazquez, J. J., and Dixon, F. J., Immunohistochemical study of lesions in rheumatic fever, systemic lupus erythematosus and rheumatoid arthritis, Lab. Inv., 1957, 6, 205.

17. McKee, A. P., and Jeter, W. S., The demonstration of an antibody against complement, J. Immunol., 1956, 76, 112.

18. Freedman, P., and Markowitz, A. S., Gamma globulin and complement in the diseased kidney, J. Clin. Inv., 1962, 41, 328.

19. Farr, R. S., A quantitative immunochemical measure of the primary interaction between I*BSA and antibody, J. Infect. Dis., 1958, 103, 239.

20. Kabat, E. A., and Mayer, M. M., Experimental Immunochemistry, Springfield, Illinois, Charles C. Thomas, 1961.

21. Osler, A. G., Strauss, H., and Mayer, M. M., Diagnostic complement fixation method, Am. J. Syph., Gon. and Ven. Dis., 1952, 36, 140.

22. Stavitsky, A. B., Hackel, D. B., and Heymann, W., Reduction of serum $\mathrm{C}^{\prime}$ following in vivo tissue antigen-antibody reactions, Proc. Soc. Exp. Biol. and Med., 1954, 85, 593.

23. Ishizaka, K., and Ishizaka, T., Biologic activity of aggregated gamma globulin. II. A study of various methods for aggregation and species differences, $J$. Immunol., 1960, 85, 163.

24. Stavitsky, A. B., Heymann, W., and Hackel, D. B., Relation of complement fixation to renal disease in rats injected with duck antikidney serum, J. Lab. and Clin. Med., 1956, 47, 349.

25. Smadel, J. E., Experimental nephritis in rats induced by injection of anti-kidney serum. III. Pathological studies of the acute and chronic disease, J. Exp. Med., $1937,65,541$.

26. Heymann, W., and Lund, H. Z., Nephrotic syndrome in rats, Pediatrics, 1951, 7, 691 . 
27. Hasson, M. W., Bevans, M., and Seegal, B. C., Immediate or delayed nephritis in rats produced by duck anti-rat-kidney sera, Arch. Path., 1957, 64, 192.

28. Ortega, L. G., and Mellors, R. C., Analytical pathology. IV. The role of localized antibodies in the pathogenesis of nephrotoxic nephritis in the rat, J. Exp. Med., 1956, 104, 151.

29. Seegal, B. C., Hsu, K. C., Rothenberg, M. S., and Chapeu, M. L., Studies of the mechanism of experimental nephritis with fluorescein-labeled antibody. II. Localization and persistence of injected rabbit or duck anti-rat-kjdney serum during the course of nephritis in rats, Am. J. Path., 1962, 41, 183.

30. Kurtz, H. M., and Donnell, G. N., The effect of depression of plasma complement on nephrotoxic renal disease in rats, Bact. Proc., 1962, 87.

31. Lange, K., Wenk, E. J., Wachstein, M., and Noble, J., The mechanism of experimental glomerulonephritis produced in rabbits by avian anti-kidney sera, Am. J. Med. Sc., 1958, 236, 767.

\section{EXPLANATION OF PLATES}

Plate 64

Fig. 1. Glomerulus from control rat injected with normal rabbit serum. Hematoxylin and eosin. $\times 325$.

Fig. 2. Hypercellular glomerulus from rat given RGG at birth and sacrificed 3 days after injection of purified rabbit nephrotoxic gamma globulin. Some of the capillary lumens are occluded by proliferation and swelling of endothelial cells and the glomerulus is enlarged filling Bowman's space. Hematoxylin and eosin. $\times 325$. 


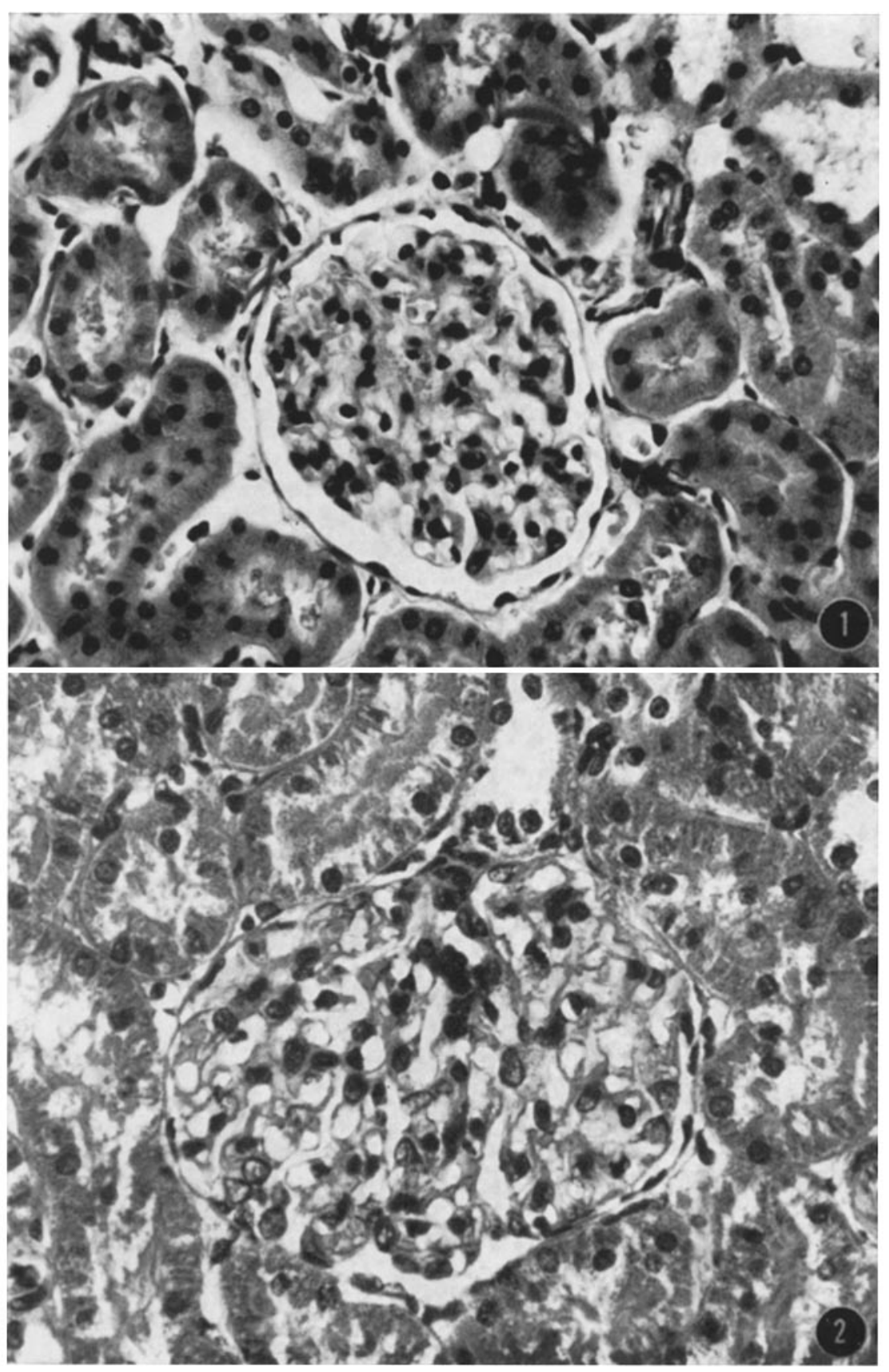

(Hammer and Dixon: Pathogenesis of nephrotoxic serum nephritis) 
Plate 65

FIG. 3. Glomerulus from normal rat 8 days after injection of RNTS. There is increased cellularity and most of the capillary lumina are occluded. PAS stain of adjuvant section showed thickened capillary basement membranes. The glomerulus is enlarged and completely fills Bowman's space. Hematoxylin and eosin. $\times 325$.

Fig. 4. Glomerulus from rat given RGG at birth, 4 weeks after injection with purified nephrotoxic gamma globulin. There is still a slight increase of cellularity, but most of the glomerular capillaries are patent. The glomerular capillary basement membranes remain thickened. Hematoxylin and eosin. $\times 325$. 


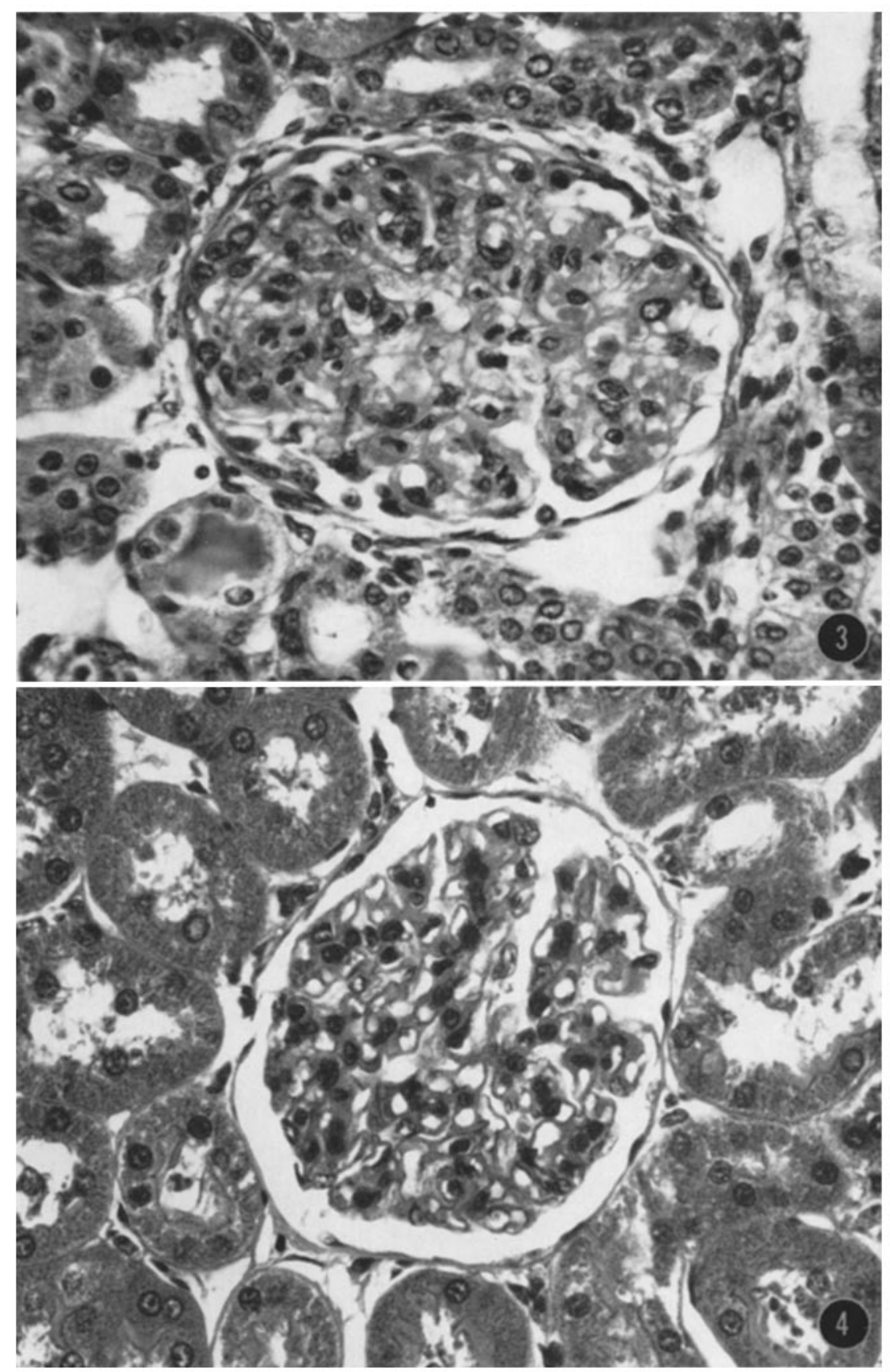

(Hammer and Dixon: Pathogenesis of nephrotoxic serum nephritis) 
Plate 66

FIG. 5. Kidney section from rat given RGG at birth, 12 weeks after injection of RNTS. Stained with fluorescent sheep antirabbit gamma globulin, glomerulus shows bright, specific fluorescence of RGG, apparently localized in the basement membranes. Fluorescence micrograph. $\times 350$.

FIG. 6. Fluorescence photomicrograph of a kjdney section from normal rat given RNTS and sacrificed 1 day later. Section exposed to rabbit antirat complement shows bright fluorescence along glomerular capillaries slightly more diffuse than seen in sections stained for RGG. $\times 400$. 

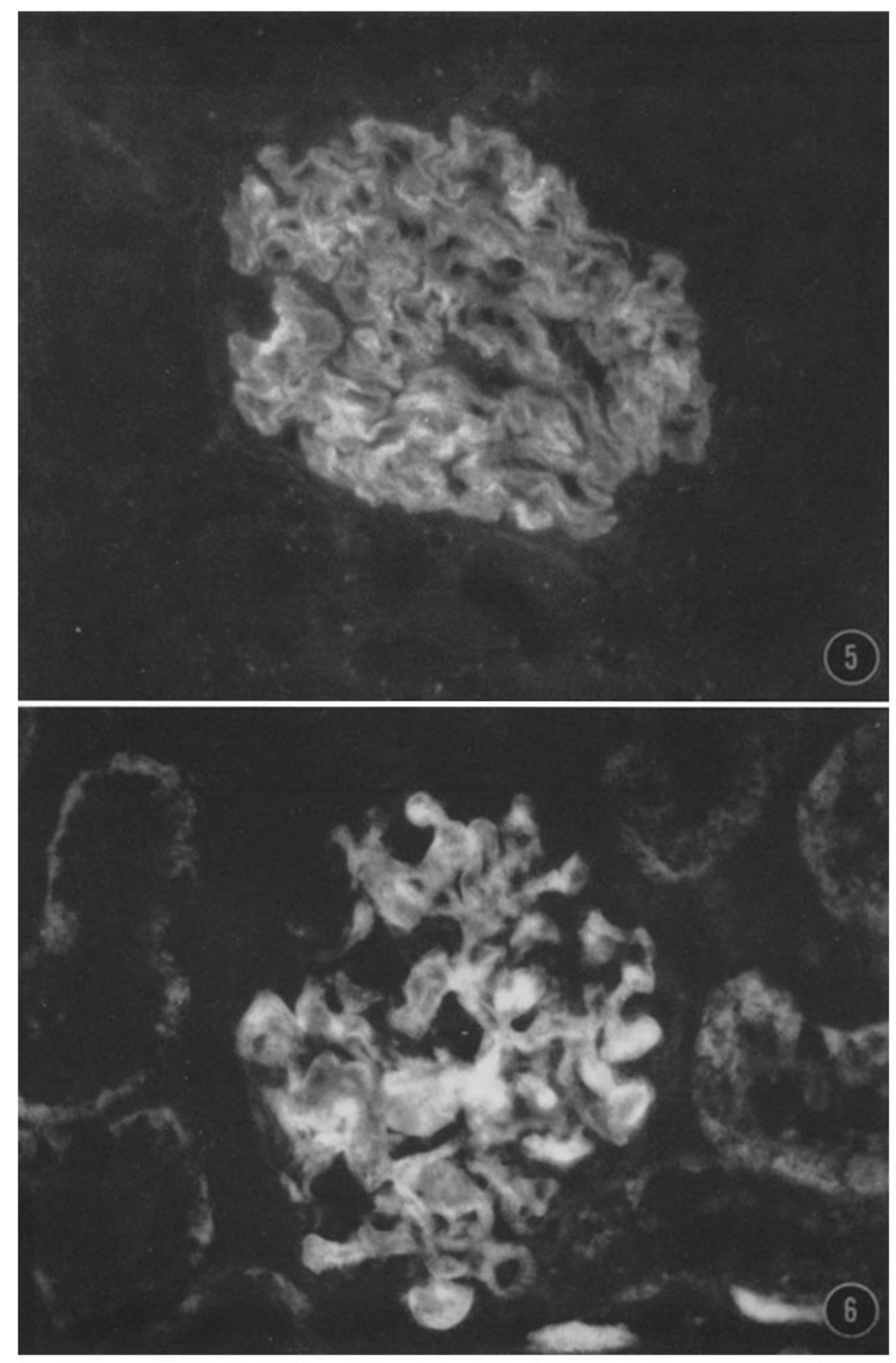

(Hammer and Dixon: Pathogenesis of nephrotoxic serum nephritis) 


\section{Plate 67}

FIG. 7. Glomerulus from normal rat receiving aggregated HGG 1 hour prior to injection of RNTS. The rat was sacrificed 20 minutes after injection of RNTS and the section stained with rabbit antirat complement. Most of the glomeruli did not show specific fluorescence, indicating failure of fixation of complement. Fluorescence micrograph. $\times 350$.

FIG. 8. Glomerulus from normal rat 12 weeks after injection of RNTS. Glomerulus shows proliferation and marked fibrosis and scarring. Hematoxylin and eosin. $\times 325$. 


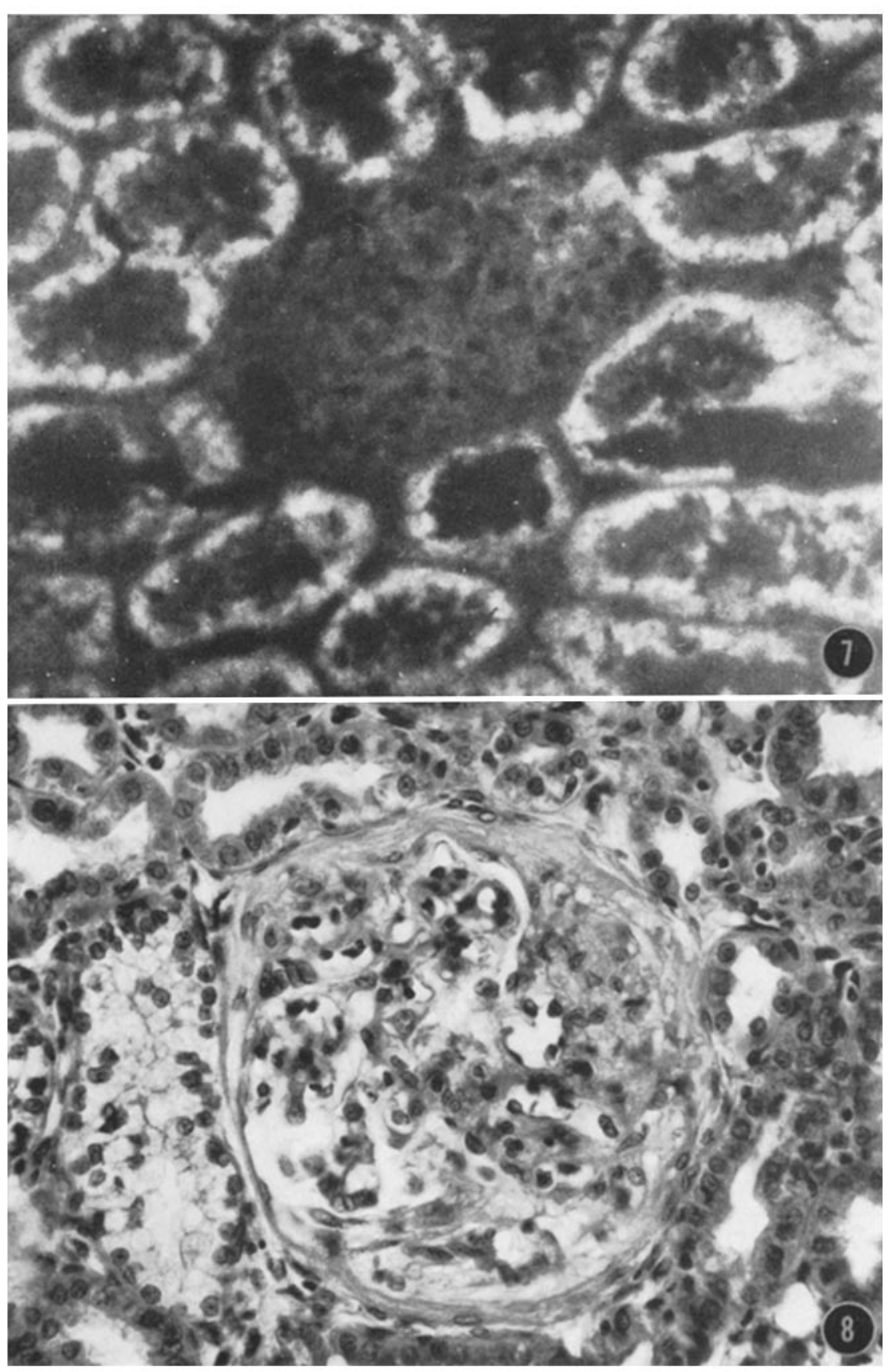

(Hammer and Dixon: Pathogenesis of nephrotoxic serum nephritis) 
Frg. 9. Glomerulus from rat given RGG at birth and sacrificed 8 weeks after injection of RNTS. The rat had received rat antirabbit gamma globulin 5 days after injection of RNTS. The glomerular architecture is distorted by extensive adhesions and scarring. Glomerular basement membranes are thickened. Note splitting and thickening of Bowman's capsule. One protein cast is present in the tubule at the upper right. PAS. $\times 325$.

FIG. 10. Kidney section from normal rat given RNTS 8 weeks previously and stained with rabbit antirat gamma globulin. The fluorescence indicates concentration of host gamma globulin in glomerulus. Some fluorescence is present in tubules, presumably casts containing rat gamma globulin. Fluorescence micrograph. $\times 350$. 

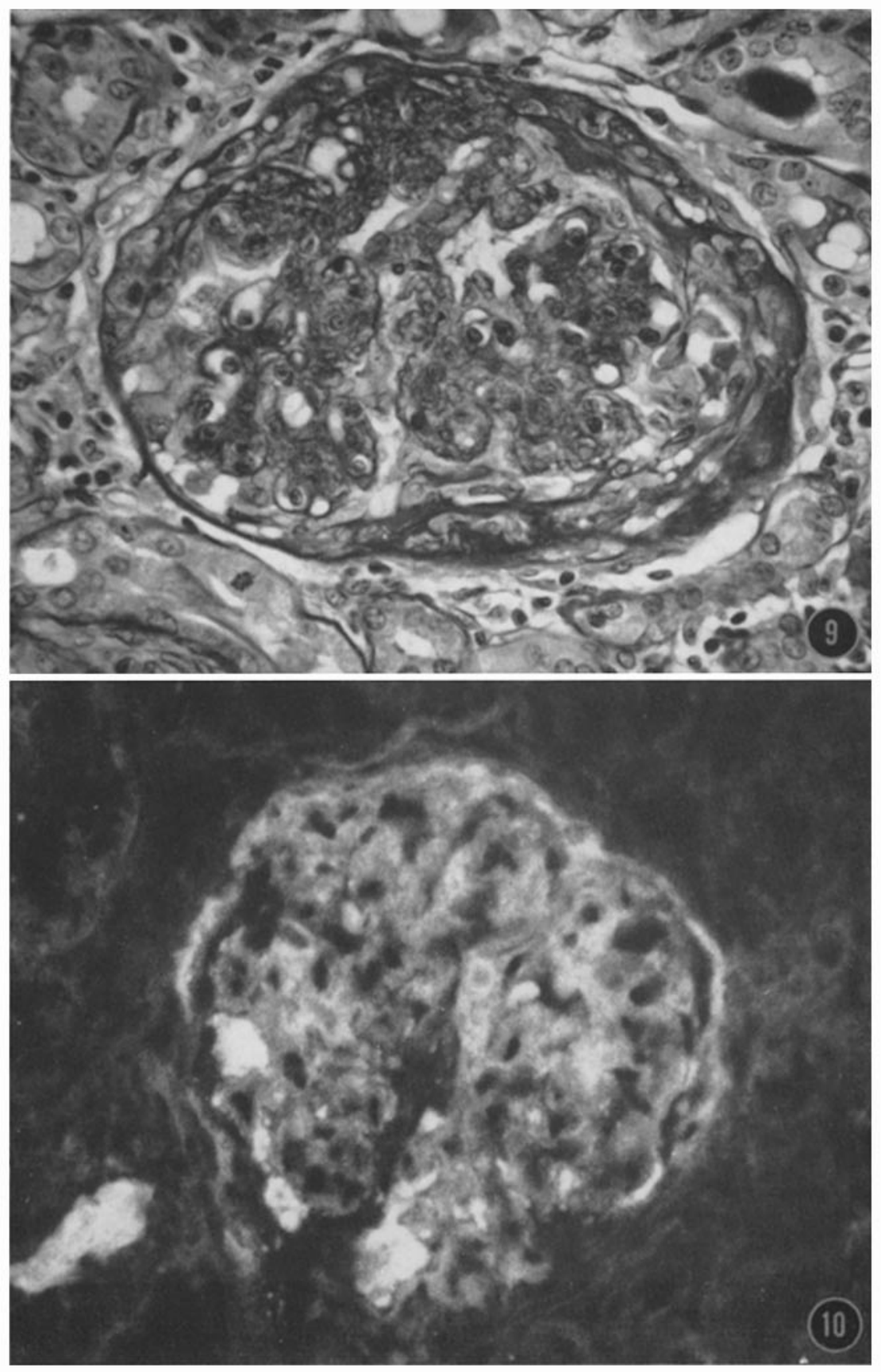

(Hammer and Dixon: Pathogenesis of nephrotoxic serum nephritis) 